\title{
Survival outcomes of the NeoALTTO study (BIG 1-06): updated results of a randomised multicenter phase III neoadjuvant clinical trial in patients with HER2-positive primary breast cancer ${ }^{\text {मै }}$
}

Jens Huober ${ }^{\mathrm{a}, *}$, Eileen Holmes ${ }^{\mathrm{b}}$, José Baselga ${ }^{\mathrm{c}}$, Evandro de Azambuja ${ }^{\mathrm{d}}$, Michael Untch ${ }^{\mathrm{e}}$, Debora Fumagalli ${ }^{\mathrm{f}}$, Severine Sarp ${ }^{\mathrm{g}}$, Istvan Lang ${ }^{\mathrm{h}}$, Ian Smith ${ }^{\mathrm{i}}$, Frances Boyle ${ }^{\mathrm{j}}$, Binghe $\mathrm{Xu}{ }^{\mathrm{k}}$, Christophe Lecocq ${ }^{\mathrm{d}}$, Hans Wildiers ${ }^{1}$, Christelle Jouannaud ${ }^{\mathrm{m}}$, John Hackman ${ }^{\mathrm{n}}$, Lokanatha Dasappa ${ }^{\circ}$, Eva Ciruelos ${ }^{\mathrm{p}}$, Juan Carlos Toral Pena ${ }^{\mathrm{q}}$, Hryhoriy Adamchuk ${ }^{\mathrm{r}}$, Tamas Hickish ${ }^{\mathrm{s}}$, Lorena de la Pena ${ }^{\mathrm{t}}$, Christian Jackisch ${ }^{\mathrm{u}}$, Richard D. Gelber ${ }^{\mathrm{v}}$, Martine Piccart-Gebhart ${ }^{\mathrm{w}}$, Serena Di Cosimo x,y

${ }^{a}$ University of Ulm, Breast Center, Ulm, Germany

${ }^{\mathrm{b}}$ Frontier Science (Scotland) Ltd, Grampian View, Kincraig, Kingussie, United Kingdom

${ }^{\mathrm{c}}$ Executive Vice President, Research \& Development Oncology, AstraZeneca, United Kingdom

${ }^{\mathrm{d}}$ Institut Jules Bordet and Breast European Adjuvant Study Team, Brussels, Belgium

${ }^{\mathrm{e}}$ Head of Breast Cancer Center, Department of Gynecology, Gynecologic Oncology and Obstetrics, HELIOS Klinikum Berlin, Buch, Germany

${ }^{\mathrm{f}}$ Breast International Group, Brussels, Belgium

g Novartis Pharma AG, Oncology Development Unit, Basel, Switzerland

${ }^{\mathrm{h}}$ Istenhegyi Gendiagnosztika Private Health Center, Oncology Clinic, Budapest, Hungary

${ }^{i}$ Royal Marsden Hospital and Institute of Cancer Research, London, UK

${ }^{\mathrm{j}}$ Patricia Ritchie Centre for Cancer Care and Research, The University of Sydney, Mater Hospital, North Sydney, Australia

${ }^{\mathrm{k}}$ Cancer Hospital, Chinese Academy of Medical Sciences, Beijing, China

${ }^{1}$ KU Leuven - University of Leuven, Department of General Medical Oncology, University Hospitals Leuven, B-3000,

Leuven, Belgium

${ }^{\mathrm{m}}$ CRLCC Jean Godinot, Reims, France

${ }^{\mathrm{n}}$ Marien-Hospital Witten, Witten, Germany

${ }^{\circ}$ Kidwai Memorial Institute of Oncology, Bangalore, India

${ }^{\mathrm{p}}$ Hospital Doce de Octubre, Madrid, Spain

${ }^{\mathrm{q}}$ Hospital Torrevieja-Salud, Torrevieja, Spain

${ }^{\mathrm{r}}$ Krivoy Rog City Oncology Centre, Krivoy Rog, Ukraine

${ }^{s}$ Royal Bournemouth Hospital \& Bournemouth University, Bournemouth, United Kingdom

\footnotetext{
The study has been presented in part at the annual meeting of the American Society of Clinical Oncology in 2017 in the poster discussion session.

* Corresponding author: University of Ulm, Breast Center, Prittwitzstrasse 43, 89075, Ulm, Germany. Fax: +49 73150058502

E-mail address: jens.huober@uniklinik-ulm.de (J. Huober).
} 
${ }^{\mathrm{t}}$ SOLTI - Breast Cancer Research Group, Barcelona, Spain

" Sana Klinikum Offenbach, Offenbach, Germany

${ }^{v}$ Department of Data Sciences, Dana-Farber Cancer Institute, Harvard Medical School, Harvard T.H. Chan School of Public

Health and Frontier Science and Technology Research Foundation, Boston, USA

${ }^{\mathrm{w}}$ Department of Medicine, Institut Jules Bordet, Université Libre de Bruxelles, Brussels, Belgium

${ }^{\mathrm{x}}$ Fondazione IRCCS Istituto Nazionale dei Tumori, Milan, Italy

${ }^{\mathrm{y}}$ SOLTI Breast Cancer Research Group, Barcelona, Spain

Received 22 January 2019; received in revised form 16 April 2019; accepted 27 April 2019

Available online 1 August 2019

\section{KEYWORDS \\ Breast cancer; HER2 positive; Neoadjuvant}

\begin{abstract}
Background: Lapatinib (L) plus trastuzumab (T) with weekly paclitaxel significantly increased the pathologic complete response (pCR) rate compared with the anti-human epidermal growth factor receptor 2 (HER2) agent alone plus paclitaxel. The event-free survival (EFS) and overall survival (OS) by the treatment arms $\mathrm{L}+\mathrm{T}$ vs. $\mathrm{T}$ and $\mathrm{L}$ vs. $\mathrm{T}$ and the relationship between pCR and EFS/OS both in the whole study population and according to hormone receptor-negative and hormone receptor-positive cohorts after a median followup of 6.7 years were assessed.
\end{abstract}

Patients and methods: Four hundred fifty-five patients with HER2-positive early breast cancer randomly received $\mathrm{L} 1500 \mathrm{mg} /$ day $(\mathrm{n}=154)$, $\mathrm{T}$ (common dose, $\mathrm{n}=149$ ) or $\mathrm{L} 1000 \mathrm{mg} /$ day plus $\mathrm{T}(\mathrm{n}=152)$ for 6 weeks, followed by the assigned anti-HER 2 treatment combined with paclitaxel weekly $\times 12$. After surgery, patients received 3 cycles of fluorouracil, epirubicin and cyclophosphamide. The primary end-point was pCR (ypT0/is; for current analysis, it is ypT0/ is ypN0), and the secondary end-points were EFS and OS.

Results: Six-year EFS rates were $67 \%, 67 \%$ and $74 \%$ with L, T and L + T, respectively (L vs T: hazard ratio [HR], 0.98 [95\% confidence interval $\{\mathrm{CI}\}, 0.64-1.51 ; P=.93]$; $\mathrm{L}+\mathrm{T}$ vs T: HR, 0.81 [95\% CI, 0.52-1.26; $P=.35]$ ). Six-Year OS rates were $82 \%, 79 \%$ and $85 \%$ for $\mathrm{L}$, $\mathrm{T}$ and $\mathrm{L}+\mathrm{T}$, respectively (L vs T: HR, $0.85[95 \% \mathrm{CI}, 0.49-1.46 ; P=.56] ; \mathrm{L}+\mathrm{T}$ vs T: HR, 0.72 [95\% CI, $0.41-1.27 ; P=.26]$ ). In landmark analyses, patients with a pCR had a significantly higher 6-year EFS (77\% and 65\%) and OS (89\% and 77\%) compared with those without a pCR for both overall and the hormone receptor-negative cohort.

Conclusion: Achieving a pCR is important in HER2-positive disease and translates into better long-term outcome with regard to EFS and OS.

(C) 2019 Elsevier Ltd. All rights reserved.

\section{Introduction}

Overexpression of human epidermal growth factor receptor 2 (HER2) characterises a breast cancer phenotype with poor prognosis [1]. Therapeutic approaches to inhibit the HER2-mediated signalling in the metastatic, adjuvant or neoadjuvant setting include the monoclonal antibodies trastuzumab and pertuzumab, trastuzumab emtansine (T-DM1) and the small-molecule tyrosine kinase inhibitor lapatinib [2]. Several trials in the metastatic and neoadjuvant settings reported an increased efficacy with the use of two HER2-targeted drugs with or without chemotherapy [3-9]. In a meta-analysis involving almost 12,000 patients [10], achieving a pathologic complete response (pCR) was significantly associated with better event-free survival (EFS) and overall survival (OS), particularly in the HER2-positive $(\mathrm{N}=1989)$ and triple-negative $(\mathrm{N}=1157)$ populations (hazard ratio [HR] 0.39/0.25 for EFS and HR 0.34/0.19 for OS). A recently published metaanalysis including 5768 HER2-positive patients from 36 trials confirmed improved EFS and OS when achieving a pCR compared with no pCR [11]. This association was greater for patients with a hormone receptor-negative disease than those with a hormone receptor-positive disease (HR, 0.29 [95\% confidence interval $\{\mathrm{CI}\}, 0.24-0.36] ; \mathrm{HR}, \quad 0.52 \quad[95 \% \mathrm{CI}$, $0.40-0.66]$, respectively).

A previous report of the NeoALTTO trial showed that lapatinib (L) and trastuzumab (T) combined with weekly paclitaxel significantly increased the rate of pCR compared with trastuzumab and weekly paclitaxel $(\mathrm{T}+\mathrm{L}, 51.3 \%$ vs. $29.5 \%$, respectively; $P=.0001)$. No significant differences were seen between $\mathrm{T}$ and $\mathrm{L}$ alone [12]. pCR rates were higher in all three arms of the NeoALTTO trial for the hormone receptor-negative 
cohort than those in the hormone receptor-positive cohort.

In the first planned survival follow-up analysis of the NeoALTTO trial [13], patients who achieved a pathological complete remission had a significantly better EFS and OS after a median follow-up of 3.84 years. EFS, however, was not significantly different between the three arms (3-year EFS rates of $76 \%, 78 \%$ and $84 \%$ for $\mathrm{T}$, $\mathrm{L}$, and $\mathrm{T}+\mathrm{L}$, respectively).

Here, we report the updated outcome results of the 455 patients enrolled in the NeoALTTO trial with regard to the secondary end-points EFS and OS and their relationship with the pCR at a median follow-up of 6.7 years.

\section{Methods}

\subsection{Study design and patients}

The design of the NeoALTTO trial was previously reported in detail $[12,13]$. In brief, 455 patients with operable, unilateral, non-inflammatory, HER2-positive early breast cancer were randomised between 5th January 2008 and 27th May 2010 to receive either L $1500 \mathrm{mg} /$ day $(\mathrm{n}=154)$, a loading dose of $\mathrm{T} 4 \mathrm{mg} / \mathrm{kg}$ followed by $2 \mathrm{mg} / \mathrm{kg} / \mathrm{wk}(\mathrm{n}=149)$ or $\mathrm{L} 1000 \mathrm{mg} /$ day plus the same dose of $\mathrm{T}(\mathrm{n}=152)$ for 6 weeks, followed by the assigned anti-HER 2 treatment combined with weekly paclitaxel $\left(80 \mathrm{mg} / \mathrm{m}^{2}\right) \times 12$. According to a protocol amendment in 2008, the lapatinib dose was reduced to $750 \mathrm{mg} /$ day in combination with paclitaxel and trastuzumab because of toxicity (diarrhoea). In total, 54 of 152 patients received this reduced dose. After surgery, patients received 3 cycles of fluorouracil, epirubicin and cyclophosphamide every 3 weeks. The assigned anti-HER2 treatment was continued for 34 weeks thereafter.

The eligibility criteria included women with tumours of $>2 \mathrm{~cm}$ and histologically confirmed HER $2+\mathrm{BC}$ defined as IHC $3+$ or a FISH ratio of $>2.2$. The HER2 status was assessed locally (after laboratory accreditation) or centrally (Vall D'Hebron Institute of Oncology, Barcelona). Hormone receptors were locally tested and considered positive as per local guidelines. Left ventricular ejection fraction at baseline had to be $\geq 50 \%$.

The primary end-point was pCR and was defined as the absence of invasive tumour cells in the breast at the time of surgery [11]. The secondary end-points included the absence of invasive cancer in the breast and ipsilateral axillary lymph nodes at surgery (ypT0/is ypN0), which will always be referred to in this analysis, diseasefree survival, EFS (added by an amendment in 2013 to align with the US Food and Drug Administration recommendations), OS, safety and tolerability. EFS was defined as the time from randomisation to the first EFS event. For women who underwent breast cancer surgery $(\mathrm{n}=427)$, EFS events were defined as post-surgery breast cancer relapse, second primary malignancy or death without recurrence. For women who did not undergo breast cancer surgery $(n=28)$, EFS events were death during clinical follow-up or non-completion of any neoadjuvant investigational product due to disease progression. The NeoALTTO trial was powered to detect treatment differences with respect to the pCR rate, but is underpowered to detect moderate treatment differences with respect to EFS and OS, and both analyses (EFS/OS) are intended to be descriptive.

\subsection{Statistical analysis}

Differences in EFS and OS between the trastuzumab group and each of the lapatinib-containing groups are described using HRs and 95\% CIs with p-values from two-sided stratified log-rank tests, implemented as Wald tests from the Cox models [14]. Tests of proportionality were performed. All 455 patients (i.e. the ITT population) were included in these analyses.

Associations between pCR and EFS/OS were examined using landmark analysis, which adjusts for guarantee-time bias [15]. For EFS, the 30-week landmark population included only women who were still in clinical (survival) follow-up and were event free (alive) at 30 weeks after randomisation (online table1). For OS, being in clinical (survival) follow-up at 30 weeks after randomisation was sufficient for inclusion, irrespective of event-free status (online table 2). The 30-week landmark time was selected as it would be sufficiently long for primary breast cancer surgery to be performed and not too long to eliminate the occurrence of EFS events. The patients were allocated to two groups according to their pCR status recorded up to week 30 from randomisation, and these groups were compared with respect to EFS/OS. Two-sided stratified log-rank tests of EFS/OS were implemented as Wald tests from the Cox model [15], with pCR status and assigned treatment arm fitted as covariates and the stratification factors entered as strata variables.

Analyses were performed with SAS (version 9.3). This trial is registered with ClinicalTrials.gov, NCT00553358.

\section{Results}

This report describes the planned updated analysis of the NeoALTTO trial after a median of 6.7 years of follow-up (interquartile range, 5.7-6.8 years). Patient characteristics were described previously [12]. The stratification factors were well balanced between the 3 treatment groups (online Table 3). The updated trial profile in the intent-to-treat population is shown in online Fig. 1. The study drug administration and toxicities of the different treatment arms were shown 
Table 1

Types of the first event-free survival (EFS) event.

\begin{tabular}{|c|c|c|c|c|}
\hline & $\begin{array}{l}\text { Lap + Tras } \\
(\mathrm{N}=152)\end{array}$ & $\begin{array}{l}\text { Lap } \\
(\mathrm{N}=154)\end{array}$ & $\begin{array}{l}\text { Tras } \\
(\mathrm{N}=149)\end{array}$ & $\begin{array}{l}\text { Overall } \\
(\mathrm{N}=455)\end{array}$ \\
\hline No. of EFS events ${ }^{a}$ & $38(25 \%)$ & $44(29 \%)$ & $45(30 \%)$ & $127(28 \%)$ \\
\hline Distant metastasis & $18(12 \%)$ & $29(19 \%)$ & $27(18 \%)$ & $74(16 \%)$ \\
\hline CNS & 9 & 6 & 8 & 23 \\
\hline Visceral (not CNS) & 4 & 15 & 10 & 29 \\
\hline Bone & 3 & 7 & 5 & 15 \\
\hline Other distant & 2 & 1 & 4 & 7 \\
\hline $\begin{array}{l}\text { Locoregional } \\
\text { recurrence }\end{array}$ & $11(7 \%)$ & $8(5 \%)$ & $5(3 \%)$ & $24(5 \%)$ \\
\hline $\begin{array}{l}\text { Second primaries in } \\
\text { the same or } \\
\text { contralateral } \\
\text { breast }\end{array}$ & $3(2 \%)$ & $0(0 \%)$ & $6(4 \%)$ & $9(2 \%)$ \\
\hline $\begin{array}{l}\text { Second (non-breast) } \\
\text { primaries }\end{array}$ & $3(2 \%)$ & $3(2 \%)$ & $4(3 \%)$ & $10(2 \%)$ \\
\hline Other EFS events ${ }^{\mathrm{b}}$ & $3(2 \%)$ & $4(3 \%)$ & $3(2 \%)$ & $10(2 \%)$ \\
\hline
\end{tabular}

Lap, lapatinib; Tras, trastuzumab; CNS, central nervous system.

${ }^{\text {a }}$ Patients with multiple sites at the time of the first EFS event appear only once in the table in the uppermost category that applies.

b Includes progression or second primary breast cancer during neoadjuvant treatment $[1,1,1]$; death during clinical follow-up (no surgery) $[1,1,1]$; or death during clinical follow-up (after surgery) $[1,2,1]$.

elsewhere [12,13]. In brief, of the ITT population $(\mathrm{n}=455), 448$ patients started neoadjuvant therapy; $102(66 \%), 138(93 \%), 92(61 \%)$ and $137(90 \%)$ completed the neoadjuvant phase as planned with

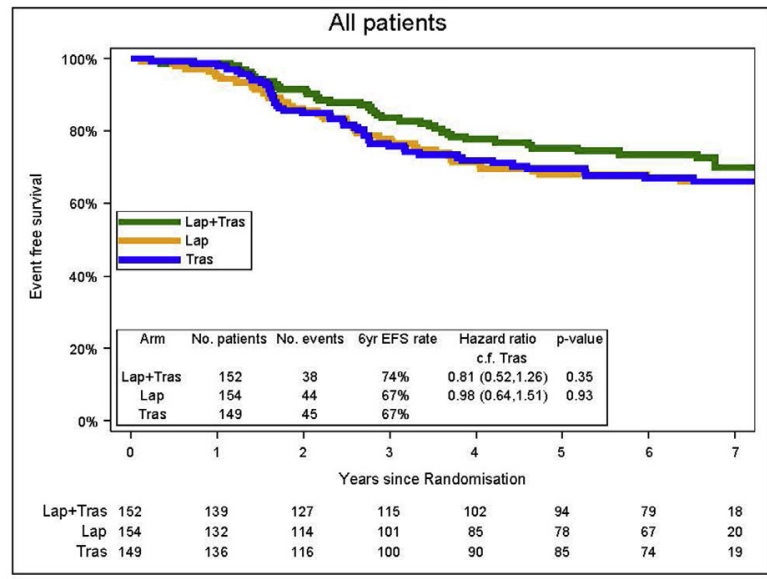

Tests for interaction:

Lap + Tras vs Tras $x$ hormone receptor status $p=0.87$ Lap vs Tras $x$ hormone receptor status $p=0.49$ lapatinib in $\mathrm{L}$, trastuzumab in $\mathrm{T}$, lapatinib in $\mathrm{L}+\mathrm{T}$ and trastuzumab in $\mathrm{L}+\mathrm{T}$, respectively. Adjuvant treatment was completed as planned in the respective treatment groups by 99 patients $(64 \%)$ in L, $121(81 \%)$ in $\mathrm{T}, 99$ $(65 \%) \mathrm{L}$ in $\mathrm{L}+\mathrm{T}$ and $120(79 \%) \mathrm{T}$ in $\mathrm{L}+\mathrm{T}(\%$ refers to the ITT population).

Only twenty-two more EFS events occurred during the 3 additional years of follow-up since the first EFS analysis, adding up to 127 events in total: $38 / 152$ in $\mathrm{L}+\mathrm{T}, 44 / 154$ in $\mathrm{L}$ and 45/149 in $\mathrm{T}$. The types of the first event are shown in Table 1.

The 6-year EFS was $74 \%$ in the L + T group and $67 \%$ in both the $\mathrm{L}$ and $\mathrm{T}$ groups (Fig. 1). The EFS in $\mathrm{L}+\mathrm{T}$ was not statistically different compared with that in $\mathrm{T}$ (HR, $0.81[95 \% \mathrm{CI}, 0.52-1.26 ; P=.35])$. In the hormone receptor-negative cohort, the 6-year EFS rate was $74 \%, 61 \%$ and $63 \%$ for the $\mathrm{L}+\mathrm{T}, \mathrm{L}$ and $\mathrm{T}$ group, respectively, (L + T vs T: HR, 0.81 [95\% CI, 0.44-1.51; $P=.52]$; L vs T: HR, 1.09 [95\% CI, 0.61-1.95; $P=.76])$.

The 6-year OS was $85 \%, 82 \%$ and $79 \%$ for the $\mathrm{L}+\mathrm{T}$, $\mathrm{L}$ and $\mathrm{T}$ groups, respectively. These differences in OS were not statistically significant $(\mathrm{L}+\mathrm{T}$ vs $\mathrm{T}$ : $\mathrm{HR}, 0.72$ [95\% CI, 0.41-1.27; $P=.26$ ]; L vs T: HR, 0.85 [95\% CI, $0.49-1.46 ; P=.56])$. There were also no significant differences across the three treatment groups when OS was analysed by the hormone receptor status (Fig. 2).
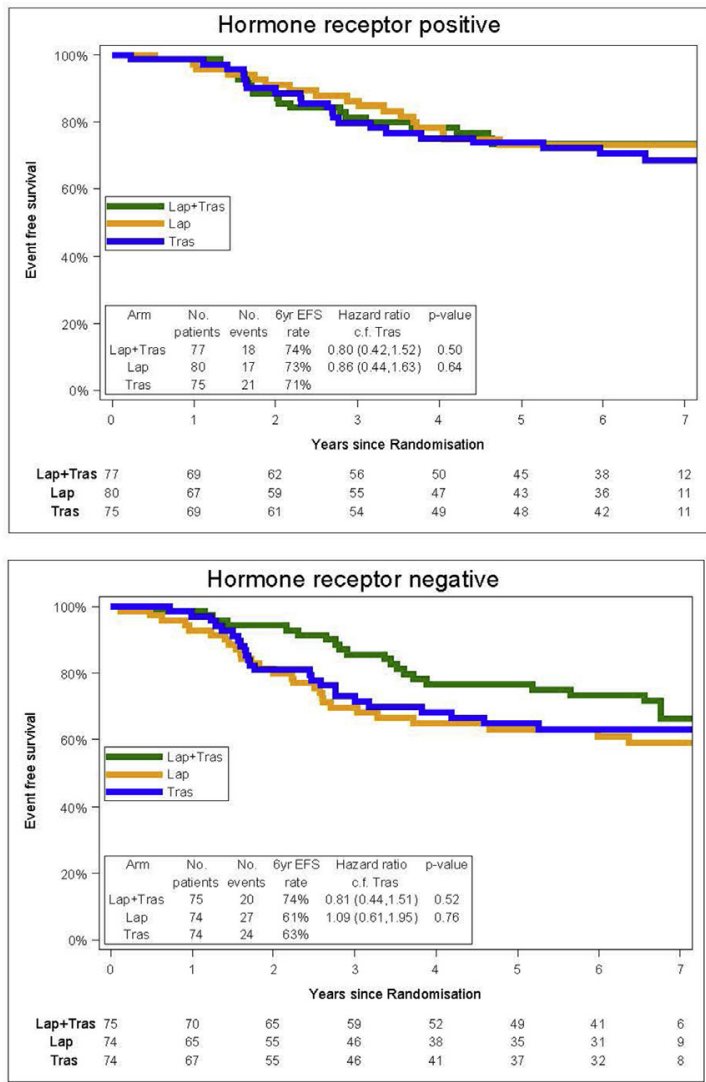

Fig. 1. Kaplan-Meier plots showing event-free survival (EFS) for each of the three treatment groups by the hormone receptor status. Lap indicates lapatinib, and Tras, trastuzumab. 


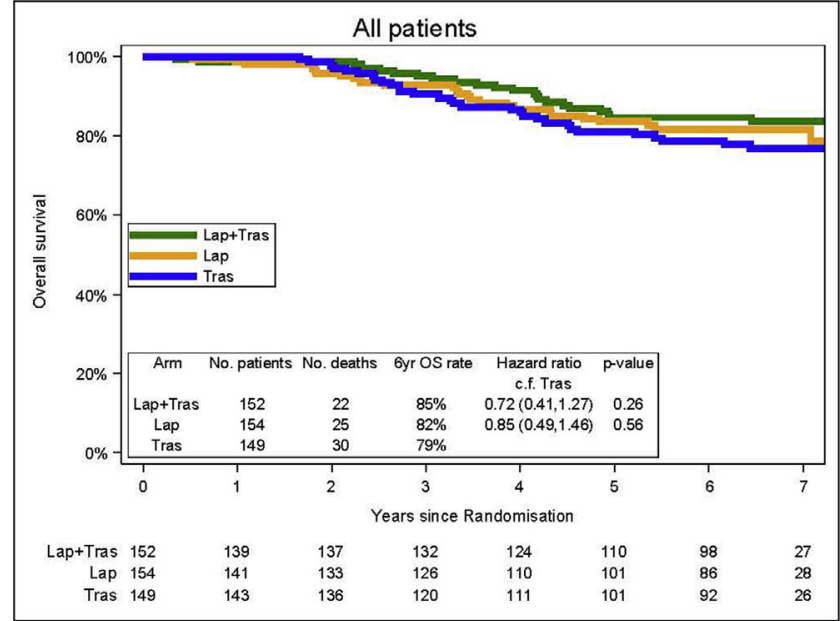

Tests for interaction:

Lap + Tras vs Tras $x$ hormone receptor status $p=0.45$ Lap vs Tras $x$ hormone receptor status $p=0.72$
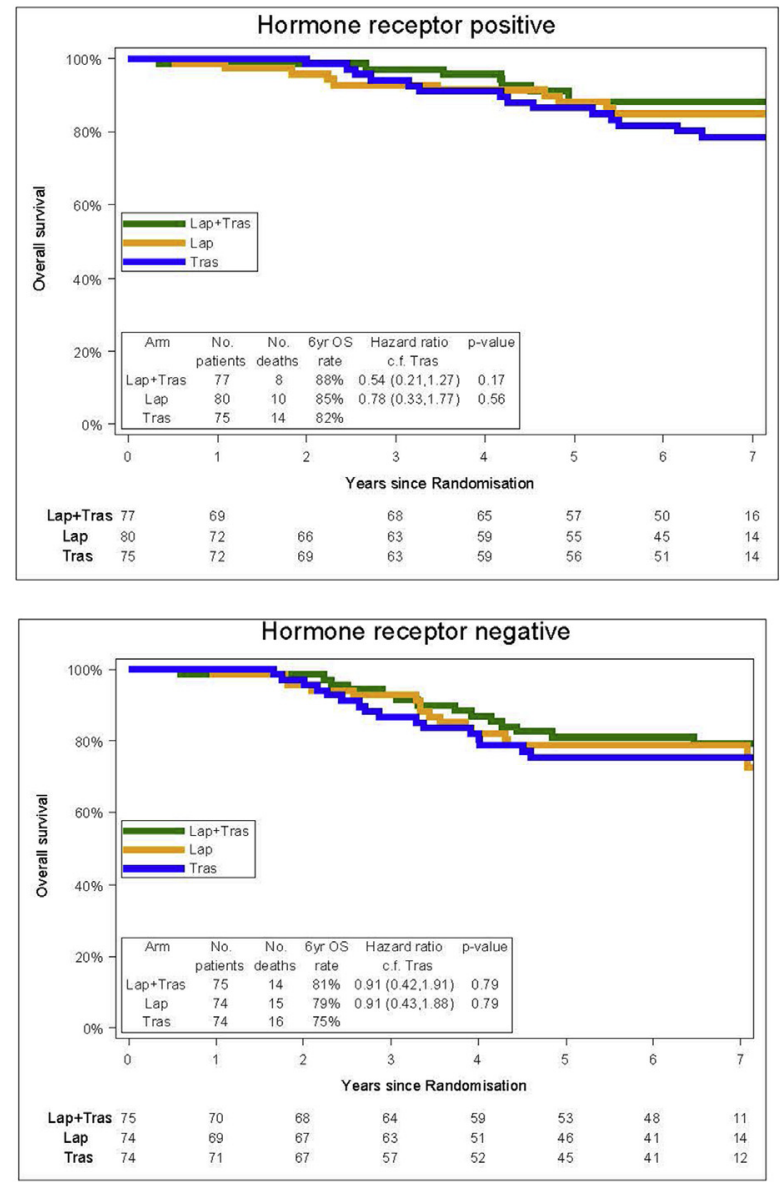

Fig. 2. Kaplan-Meier plots showing overall survival (OS) for each of the three treatment groups by the hormone receptor status. Lap indicates lapatinib, and Tras, trastuzumab.

In total, 411 patients $(90.3 \%)$ were included in the EFS landmark analysis, whereas 44 patients were excluded because of missing pCR data at landmark, an EFS event before landmark or no clinical follow-up before landmark (online Table1). Patients with a pCR had significantly higher 6-year EFS (77\% vs $65 \%$ ) than those without pCR (Fig. 3), both overall (HR, 0.54 [95\% CI, 0.34-0.82; $P=.005]$ ) and the hormone receptor-negative cohort $(77 \%$ vs $57 \%$; HR, 0.47 [95\% CI, $0.27-0.81 ; P=.008])$.

Landmark analysis for OS (online table 2) showed significantly higher 6-year OS for those with pCR than those without pCR $(89 \%$ vs $77 \%$; HR, 0.43 [95\% CI, $0.23-0.75 ; P=.005])$. The survival advantage of achieving a pCR was limited to the hormone receptor-negative cohort (HR, 0.35 [95\% CI, 0.16-0.70; $P=.005])$ (Fig. 4).

Landmark analysis according to pCR showed a significant advantage for achieving a pCR in the $\mathrm{L}+\mathrm{T}$ arm with regard to EFS (HR, 0.45 [95\% CI, 0.20-0.93; $P=.036])$ and OS (HR, 0.28 [95\% CI, 0.09-0.77; $P=.019])$. Differences according to the pCR status were less pronounced for L (HR, $0.54[95 \% \mathrm{CI}$, $0.21-1.18 ; P=.15]$ or $\mathrm{T}$ alone (HR, 0.62 [95\% CI,
$0.29-1.25 ; P=.20])$ for EFS and L (HR, $0.54[95 \% \mathrm{CI}$, $0.15-1.52 ; P=.28]$ ) or $\mathrm{T}$ alone (HR, $0.45[95 \% \mathrm{CI}$, $0.16-1.10 ; P=.10])$ for $\mathrm{OS}$; interaction tests were not statistically significant (online Figs. 2 and 3).

Since the first analysis, there were no further fatal adverse events and was one additional non-fatal adverse event. None of the patients experienced cardiac death, cardiac heart failure NYHA 3/4 since the last analysis.

\section{Discussion}

After a median follow-up of 6.7 years, the updated analysis of the NeoALTTO trial shows a significantly better EFS and OS for patients achieving a pCR after neoadjuvant anti-HER2-based therapies and receiving the same assigned anti-HER2 treatment as adjuvant therapy as in the neoadjuvant phase. The benefit of achieving a pCR was higher for patients with hormone receptor negative tumours than those with a hormone receptor-positive disease. In particular, in the HR-negative cohort, the EFS rate improved dramatically by $20 \%$, increasing the 6-year EFS rate from $57 \%$ 


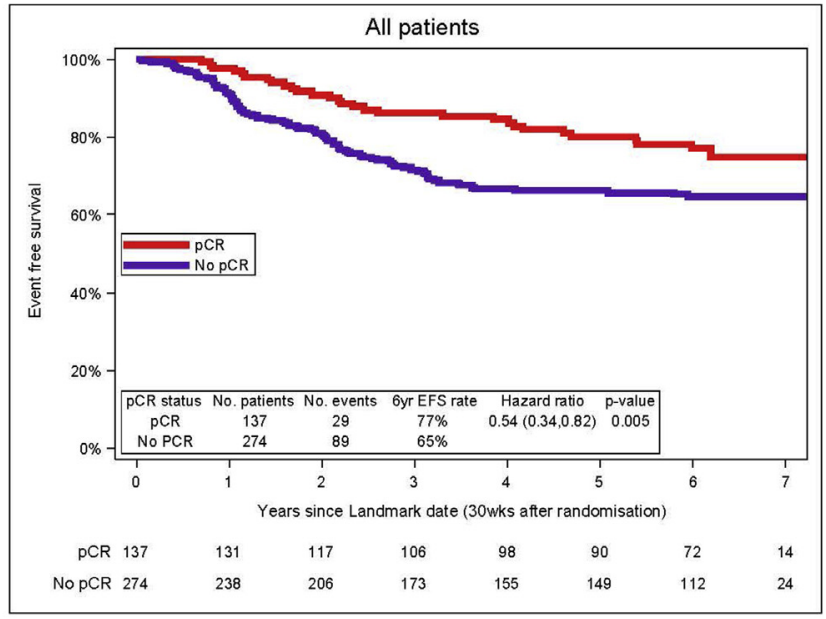

Test for interaction: $\mathrm{pCR} \times$ hormone receptor status $p=0.29$
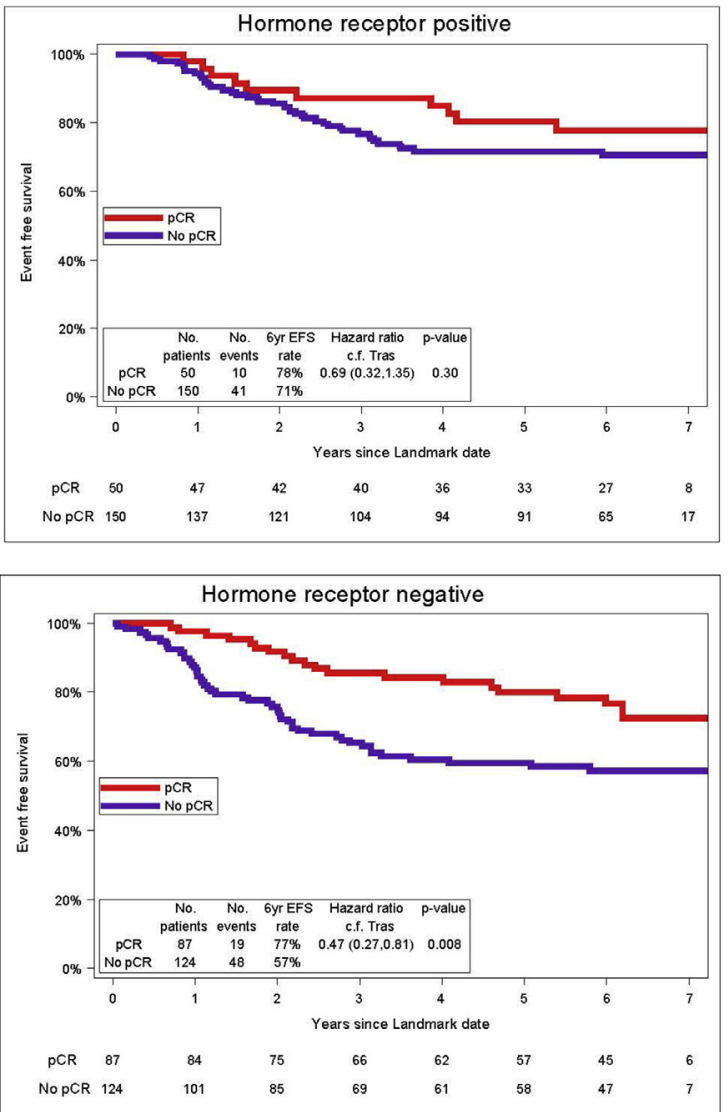

Fig. 3. Kaplan-Meier plots showing event-free survival (EFS) for the pCR and no pcR groups by the hormone receptor status. pCR indicates pathological complete remission.

to $77 \%$ when a pCR was achieved. Other trials also reported that $\mathrm{pCR}$ rates were significantly higher in the HR-negative cohort after anti-HER2-based therapy $[5,11,12,16,17]$. These data are in line with a recently published meta-analysis investigating a bigger, however, less homogenous population for the association of $\mathrm{pCR}$ and long-term outcome in HER2+ breast cancer [11]. Similar results were reported in a meta-analysis by Cortazar et al. [10] where the association between a pCR and long-term outcome was strongest in patients with triple-negative and HER $2+/ \mathrm{HR}$ - tumours.

In our update of the NeoALTTO trial, 6-year OS and EFS rates were not statistically significant between the three treatment arms, but NeoALTTO was powered to detect differences in $\mathrm{pCR}$ rates between the arms and was underpowered to detect modest treatment differences with respect to EFS and OS. Thus, statistically significant differences would have been observed only if true treatment effects were large. Of note, in our trial, the combination of $\mathrm{T}$ and $\mathrm{L}$ showed numerically higher EFS that $\mathrm{T}$, particularly in the hormone receptor negative subset (13\% fewer events). A significant EFS advantage, however, for the combination of $\mathrm{L}+\mathrm{T}$, both for overall and the HR-negative cohort, was recently shown for the smaller CALGB 40,601 trial although $\mathrm{pCR}$ rates in the breast were not significantly different between the three groups [18]. In CALGB 40,601, similar to NeoALTTO, patients with primary breast cancer were preoperatively treated with weekly paclitaxel combined with $\mathrm{T}, \mathrm{L}$ or $\mathrm{L}+\mathrm{T}$ for 16 weeks. In contrast to NeoALTTO, following anthracycline-based chemotherapy after surgery anti-HER 2 treatment was continued with $\mathrm{T}$ for 34 weeks for all patients rather than with the randomised anti-HER 2 therapy. pCR was also associated with favourable long-term outcome, most pronounced in the hormone receptor negative and HER2-enriched subtype.

All these data support the notion that the HER2+/ hormone receptor population is biologically different from the HER2+/hormone receptor + cohort. Gene expression arrays showed molecular heterogeneity of the HER2 subtypes with a much higher rate of the HER2enriched subtype in the hormone receptor/HER2+ population than the HR + population [17-20] and a higher likelihood of achieving a pCR [17-23]. Among the different HER2 subtypes, the HER2-enriched subtype is likely to have the highest activation of the HER2/ epidermal growth factor receptor pathway $[21,24]$. The dual blockade may thus be most successful in these particularly HER2-addicted cancers, and this would explain that in NeoALTTO, the association of pCR and long-term outcome was much higher (and statistically 


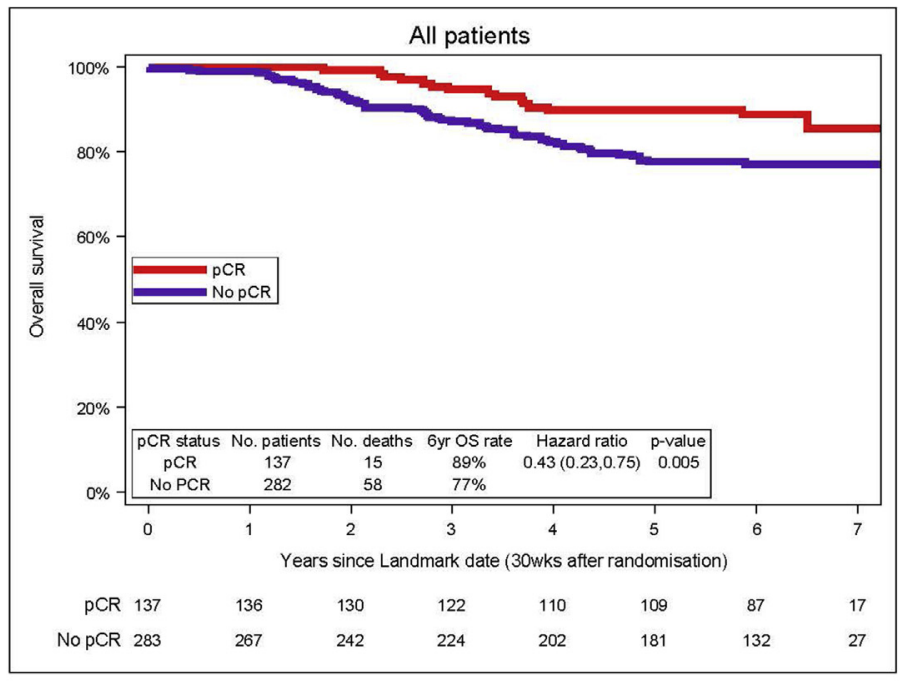

\section{Test for interaction: $\mathrm{pCR} \times$ hormone receptor status $\mathrm{p}=0.33$}
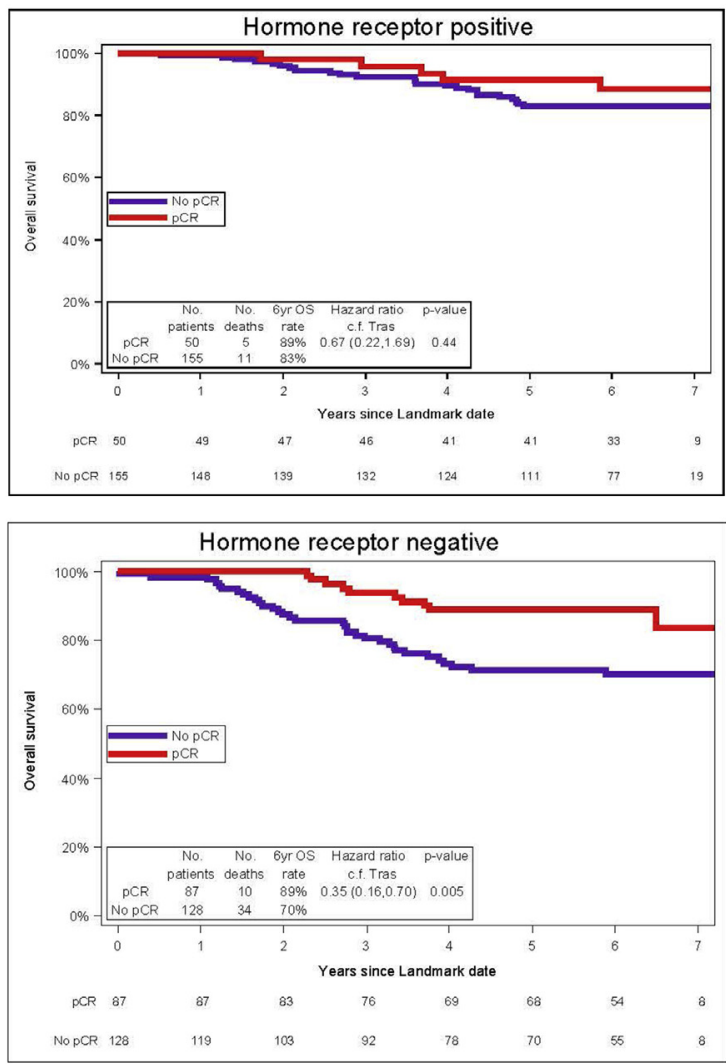

Fig. 4. Kaplan-Meier plots showing overall survival (OS) for the pCR and no pcR groups by the hormone receptor status. pCR indicates pathological complete remission.

significant) in the combination arm (19\% difference of EFS in favour of the pCR patients) than the monotherapy arms, where the difference was less evident. However in the NeoALTTO trial, a high expression of mRNA levels of ERBB2/HER2 and the HER2-enriched subtype, both predicting a higher likelihood of a pCR, were not associated with EFS after correction for multiple testing, but this analysis was underpowered [21].

Data regarding the activity of $\mathrm{L}$ as monotherapy in the neoadjuvant setting are conflicting. In the Geparquinto trial, the combination of epirubicine cyclophosphamide (EC) + docetaxel and $\mathrm{L}$ was inferior to the combination of $\mathrm{EC}+$ docetaxel and $\mathrm{T}$ with regard to the pCR rates [23,25]. By contrast, in the NSABP B-41 trial, the $\mathrm{pCR}$ rate was not decreased by the substitution of $\mathrm{T}$ with $\mathrm{L}$ in addition to a taxane-based therapy. Exploratory analyses however suggest that the three treatment arms are different in long-term outcomes [26]. In the NeoALTTO trial, similar to the CALGB 40,601 trial [17], $\mathrm{L}$ as monotherapy was not inferior to $\mathrm{T}$ both in terms of short-term and long-term outcomes. This is noteworthy to mention because in ALTTO [27,28], the adjuvant sister of the NeoALTTO trial, an inferior disease-free survival outcome with $\mathrm{L}$ compared with $\mathrm{T}$ led to a premature closure of the $\mathrm{L}$ arm by the Independent data monitoring committee (IDMC) at an interim analysis, while in NeoALTTO, observed differences between $\mathrm{L}$ and $\mathrm{T}$ were very small. Although the designs appear to be very similar, there are differences between ALTTO and NeoALTTO that may explain the apparent discrepancy. In NeoALTTO, except for the first 6 weeks, anti-HER 2 treatment was given in combination with a taxane-based chemotherapy. By contrast, in the ALTTO trial, almost all of the patients contributing to the interim analysis results were treated with a sequential approach where antiHER2 therapy followed completion of all chemotherapy. In addition, ALTTO had included a lower risk patient population (about $40 \%$ tumours $<2 \mathrm{~cm}$ and $40 \%$ of node-negative disease), which contrasts with NeoALTTO, where all patients had to have a tumour of $>2 \mathrm{~cm}$.

\section{Conclusions}

The NeoALTTO trial shows that achieving a pCR is important in HER2-positive disease and translates into a better EFS and OS. This association was more clearly seen in the hormone receptor-negative cohort and in patients assigned to the $\mathrm{L}+\mathrm{T}$ arm. EFS and OS after 6 years did not significantly differ between the 3 treatment groups although $\mathrm{L}+\mathrm{T}$ showed numerically higher EFS than $\mathrm{T}$ in the hormone receptor-negative group. This 
observation underlines that the hormone receptor-negative, HER2-positive tumours are a distinct tumour entity, which may benefit the most from dual anti-HER2 blockade.).

\section{Conflict of interest statement}

Jose Baselga is an employee of AstraZeneca, serves on the board of directors of Foghorn and is a past board member of Varian Medical Systems, Bristol-Myers Squibb, Grail, Aura Biosciences and Infinity Pharmaceuticals. He has performed consulting and/or advisory work for Grail, PMV Pharma, ApoGen, Juno, Lilly, Seragon, Novartis and Northern Biologics. He has stock or other ownership interests in PMV Pharma, Grail, Juno, Varian, Foghorn, Aura, Infinity, ApoGen, as well as Tango and Venthera, for which he is a cofounder. $\mathrm{He}$ has previously received honoraria or travel expenses from Roche, Novartis and Lilly. Severine Sarp is an employee of Novartis. Richard D. Gelber received research funding from Roche, Pfizer, AstraZeneca, Merck, Novartis, Ferring and Ipsen. Christian Jackisch received honoraria and travel and accommodation expenses from Roche and Celgene. Michael Untch received all fees and honoraria for ad boards, conference fees, travel fees, scientific talks were paid to my employer/institution from Abbvie, Amgen, Astra Zeneca, Celgene, Daiji Sankyo, Eisai, Lilly Germany, Lilly Int., MSD Merck, Mundipharma; Myriad Genetics, Novartis, Odonate, Pfizer, PUMA Biotechnology, Roche Pharma, Sanofi Aventis, TEVA Pharmaceuticals. Serena di Cosimo received speaker bureau from Novartis Pharma. Evandro de Azambuja reveived honoraria and advisory boards from Roche, travel grants from Roche and GSK/Novartis and research grant from Roche, Astra-Zeneca, GSK/ Novartis, and Servier. Jens Huober performed consulting work for Roche, Novartis, Pfizer, Celgene, AstraZeneca and Lilly; received honoraria from Roche, Novartis, Pfizer, Lilly, Eisai and Celgene; received travel expenses from Roche, Novartis, Pfizer, Daiichi and Celgene and received research funding from Novartis and Celgene.

\section{Appendix A. Supplementary data}

Supplementary data to this article can be found online at https://doi.org/10.1016/j.ejca.2019.04.038.

\section{References}

[1] Hynes NE, Stern DF. The biology of erbB-2/neu/HER-2 and its role in cancer. Biochim Biophys Acta 1994;1198:165-84.

[2] Schramm A, De Gregorio N, Widschwendter P, Fink V, Huober J. Targeted therapies in HER2-positive breast cancer - a systematic review. Breast Care 2015;10(3):173-8.
[3] Baselga J, Gelmon KA, Verma S, Wardley A, Conte P, Miles D, et al. Phase II trial of pertuzumab and trastuzumab in patients with human epidermal growth factor receptor 2-positive metastatic breast cancer that progressed during prior trastuzumab therapy. J Clin Oncol 2010;28(7):1138-44.

[4] Swain SM, Baselga J, Kim S-B, Ro J, Semiglazov V, Campone M, et al. Pertuzumab, trastuzumab, and docetaxel in HER2-positive metastatic breast cancer. N Engl J Med 2015;372(8):724-34.

[5] Gianni L, Pienkowski T, Im YH, Roman L, Tsenq LM, Liu MC, et al. Efficacy and safety of neoadjuvant pertuzumab and trastuzumab in women with locally advanced, inflammatory, or earlystageHER 2 positive breast cancer (NeoSphere): a multicenter, open label, phase 2 randomized trial. Lancet Oncol 2012;13(1): $25-32$.

[6] Gianni L, Pienkowski T, Im YH, Tsenq LM, Liu MC, Lluch A, et al. 5-year analysis of neoadjuvant pertuzumab and trastuzumab in patients with locally advanced, inflammatory, or earlystageHER2 positive breast cancer (NeoSphere): a multicenter, open label, phase 2 randomized trial. Lancet Oncol 2016;17(6): 791-800.

[7] Baselga J, Cortes J, Sung-Bae K, Seock-Ah I, Hegg R, YoungHyuck I, et al. Pertuzumab plus trastuzumab plus docetaxel for metastatic breast cancer. N Engl J Med 2012;366(2):109-19.

[8] Clavarezza M, Puntoni M, Gennari A, Paleari L, Provinciali N, D'Amico M, et al. Dual block with lapatinib and trastuzumab versus single-agent trastuzumab combined with chemotherapy as neoadjuvant treatment of HER2-positive breast cancer: a metaanalysis of randomized trial. Clin Cancer Res 2016;22(18): 4594-603.

[9] Gradishar WJ, Hegg R, Im S, Park IH, Tjulandin S, Kenny S, et al. Phase 3 study of lapatinib plus trastuzumab and aromatase inhibitor vs Tras+AI vs Lap + AI in postmenopausal women with HER2+/HR + metastatic breast cancer: Alternative. J Clin Oncol 2017;35(suppl.; abstr 1004).

[10] Cortazar P, Zhang L, Untch M, Mehta K, Costantino JP, Wolmark N, et al. Pathological complete response and long-term clinical benefit in breast cancer: the CTNeoBC pooled analysis. Lancet 2014;384(9938):164-72.

[11] Broglio KR, Quintana M, Foster M, Olinger M, McGlothlin A, Berry SM, et al. Association of pathologic complete response to neoadjuvant therapy in HER2-positive breast cancer with longterm outcomes a meta-analysis. JAMA Oncol 2016;2(6):751-60.

[12] Baselga J, Bradbury I, Eidtmann H, Di Cosimo S, de Azambuja E, Aura C, et al. Lapatinib with trastuzumab for HER2-positive early breast cancer (NeoALTTO): a randomised, open-label, multicentre, phase 3 trial. Lancet 2012;379(9816):633-40.

[13] de Azambuja E, Holmes AP, Piccart-Gebhart M, Holmes E, Di Cosimo S, Swaby RF, et al. Lapatinib with trastuzumab for HER2-positive early breast cancer (NeoALTTO): survival outcomes of a randomised, open-label, multicentre, phase 3 trial and their association with pathological complete response. Lancet Oncol 2014;15(10):1137-46.

[14] Cox R. Regression models and life tables (with discussion). J R Stat Soc B 1972;34:187-220.

[15] Anderson JR, Cain KC, Gelber RD. Analysis of survival by tumor response and other comparisons of time-to-event by outcome variables. J Clin Oncol 2008;26(24):3913-5.

[16] Robidoux A, Tang G, Rastogi P, Geyer CE, Azar CA, Atkins JN, et al. Lapatinib as a component of neoadjuvant therapy for HER2-positive operable breast cancer (NSABP protocol B-41): an open-label, randomised phase 3 trial. Lancet Oncol 2013; 14(12):1183-92.

[17] Carey LA, Berry DA, Cirrincione CT, Barry WT, Pitcher BN, Harris LN, et al. Molecular heterogeneity and response to neoadjuvant human epidermal growth factor receptor 2 targeting in CALGB 40601, a randomized phase III trial of paclitaxel plus trastuzumab with or without lapatinib. J Clin Oncol 2016;34(6): $542-9$. 
[18] Krop I, Hillmann D, Polley M, Tanioka M, Parker J, Huebner L, et al. Invasive disease-free survival and gene expression signatures in CALGB (Alliance) 40601, a randomized phase III neoadjuvant trial of dual HER2-targeting with lapatinib added to chemotherapy plus trastuzumab. SABCS 2017. GS3-02.

[19] Llombart-Cussac A, Cortes J, Pare L, Galvan P, Bermejo B, Martinez N, et al. HER2-enriched subtype as a predictor of pathological complete response following trastuzumab and lapatinib without chemotherapy in early-stage HER2-positive breast cancer (PAMELA): an open-label, single-group, multicentre, phase 2 trial. Lancet Oncol 2017;18(4):545-54.

[20] Dieci MV, Prat A, Tagliafico E, Pare L, Ficarra G, Bisagni G, et al. Integrated evaluation of PAM50 subtypes and immune modulation of pCR in HER2-positive breast cancer patients treated with chemotherapy and HER2-targeted agents in the CherLOB trial. Ann Oncol 2016;27(10):1867-73.

[21] Fumagalli D, Venet D, Ignatiadis M, Azim HA, Maetens M, Rothe F, et al. RNA sequencing to predict response to neoadjuvant anti-HER2 therapy: a secondary analysis of the NeoALTTO randomized clinical trial. JAMA Oncol 2017;3(2): 227-34.

[22] Prat A, Pascuat T, Adamo B. Intrinsic molecular subtypes of HER2 positive breast cancer. Oncotarget 2017;8(43):73362-3.

[23] Guarneri V, Dieci MV, Bisagni G, Frassoldati A, Bianchi GV, De Salvo GL, et al. De-escalated therapy for HR $+/$ HER $2+$ breast cancer patients with KI67 response after 2 weeks letrozole: results of the PerELISA neoadjuvant study. Ann Oncol 2019 [pub ahead of print].

[24] The cancer genome atlas network. Nature 2012;490:61-70.

[25] Untch M, Loibl S, Bischoff J, Eidtmann H, Kaufmann M, Blohmer JU, et al. Lapatinib versus trastuzumab in combination with neoadjuvant anthracycline-taxane-based chemotherapy (GeparQuinto, GBG 44): a randomised phase 3 trial. Lancet Oncol 2012;13(2):135-44.

[26] Robidoux A, Tang G, Rastogi P, Geyer CE, Azar CA, Atkins JN, et al. Lapatinib as a component of neoadjuvant therapy for HER2-positive operable breast cancer (NSABP protocol B-41): five years outcome of NSABP protocol B-41. J Clin Oncol 2016; 34(suppl abstract 501).

[27] Piccart-Gebhart M, Holmes E, Baselga J, de Azambuja E, Dueck AC, Viale G, et al. Adjuvant lapatinib and trastuzumab for early human epidermal growth factor receptor 2-positive breast cancer: results from the randomized phase III adjuvant lapatinib and/or trastuzumab treatment optimization trial. J Clin Oncol 2016;34(10):1034-42.

[28] Moreno-Aspitia A, Holmes E, Jackisch C, de Azambuja E, Boyle FM, Hillman DW, et al. Updated results from the phase 3 ALTTO trial (BIG 2-06; NCCTG/Alliance N063D) comparing one year of anti-HER2 therapy with lapatinib alone (L), trastuzumab alone $(\mathrm{T})$, their sequence $(\mathrm{T} \rightarrow \mathrm{L})$ or their combination $(\mathrm{L}+\mathrm{T})$ in the adjuvant treatment of HER2-positive early breast cancer. J Clin Oncol 2017;35(suppl; abstr 502). 